\title{
Exploring the quality of Grade 12 accounting education textbooks
}

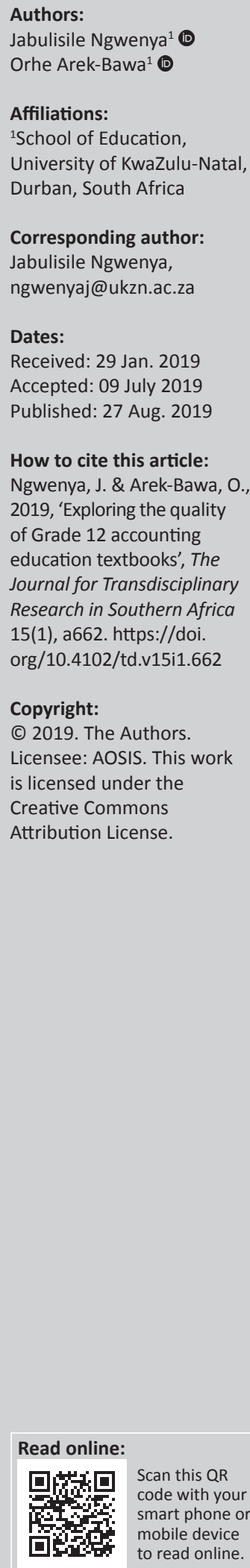

The availability of quality textbooks is one of the critical factors in the enhancement of teaching and learning in accounting. What makes a high-quality textbook depends on the presence of certain characteristics for specific subject area and curriculum requirements. However, following the reintroduction of textbooks into the South African school curriculum, there appear to be limited studies on the quality of textbooks particularly in accounting. This article explores the quality of Grade 12 accounting textbooks in terms of content, structure and organisation, guidance and support and assessment tasks. Two Grade 12 accounting textbooks were purposively sampled because of their popularity and accessibility to analyse their quality using qualitative content analysis. Findings revealed that although Book B is found to be in line with the curriculum in terms of content, Book A had a greater propensity to engage and stimulate learning as it offered better guidance and support to the teachers and learners than Book B. The identified shortfalls mean that the teachers who are using Book B will have to consult other books as the book is lacking in fully supporting teachers. The recommendation is that at least two textbooks should be prescribed especially in Grade 12 to supplement each other. This article offers insight into the quality of Grade 12 accounting textbooks used in South African Schools. It is therefore imperative for accounting teachers and subject specialists to be circumspect when choosing prescribed textbooks. The article also has implications for textbook producers and the Department of Education in their quest to enhance learning.

Keywords: Accounting textbooks; quality textbooks; accounting education; accounting curriculum; textbooks analysis.

\section{Introduction}

Research has shown that textbooks play a significant role in classrooms internationally (Chirwa \& Naidoo 2016; Freahat \& Smadi 2014; Gök 2012; Nasser \& Oqlah 2014; Swanepoel 2010; Tarman \& Kuran 2015). Teachers therefore tend to depend on the textbook that is widely used in many classrooms, sometimes up to $96 \%$ (Swanepoel 2010). The implication is that teachers use textbooks as the most dominant source of their teaching activities. Therefore, what is taught in the classroom is predominantly guided, organised and restricted to what is contained within the textbook.

The dominance of textbooks is also emphasised by the Department of Basic Education (DBE) in South Africa (Department of Education [DoE] 2009). In its attempt to improve the quality of education in South Africa, the DBE implemented the Curriculum and Assessment Policy Statement (CAPS) in 2012. This change in the curriculum has resulted in textbooks being reintroduced in classrooms as a crucial resource for learners and teachers as one of the ways of improving teaching and learning. Consequently, textbooks are regarded by the DBE as effective tools to 'ensure consistency, curriculum and assessment coverage, appropriate pacing and better quality in terms of instruction in implementing a curriculum' (DoE 2009:9). As such textbooks strongly influence what learners learn because they help teachers decide what to teach, how to teach it and what types of exercises to assign to learners (Bharath 2015; Sağlam 2012; Yang \& Sianturi 2017).

The importance of textbooks is also evident in accounting. Accounting is a discipline that requires consistent practice because of its practical nature (Abbott \& Palatnik 2018; Barac \& Du Plessis 2014; Eskola 2011; Jones \& Wright 2012). As the subject requires frequent application exercises, textbooks support teachers and learners in the learning process with suitable activities and a wide range of examples and applications that facilitate learner reflection while developing their skills and knowledge (Abbott \& Palatnik 2018; Adeoye \& Olabiyi 2011; Arek-Bawa 2018). As a result, accounting teachers rely heavily on textbooks in their day-to-day teaching for class activities and homework to give learners an opportunity to practise different skills learnt (Davidson \& Baldwin 2005; Gupta \& Marshall 2010). 
While the curriculum specifies the topics to be covered per grade, textbooks determine the content of instruction in detail such that some teachers scarcely refer to the curriculum (Bharath 2015; Sunday 2014; Widodo 2007). Textbooks therefore help teachers to structure their lessons and specify what is important on a particular topic. The logical sequencing followed in a textbook provides insight to the teacher in planning lessons and presenting the subject matter in an orderly and systematic sequence and to decide about the limits and depth of coverage of the content to be presented (Adeoye \& Olabiyi 2011; Bharath 2015). As textbooks are viewed as the most effective tools through which to deliver the curriculum and support assessments, teachers are more probable to follow strictly what is offered in the textbook. Textbooks are likely to be the key determinant of what is taught and learnt, and hence the availability of quality textbooks is crucial.

Accounting contains many unique terms and abstract knowledge which are exclusive to the discipline. Understanding these terms and concepts is regarded as the principal skill which serves as a foundation for application and analytical and evaluation skills in each accounting topic (Arek-Bawa \& Dhunpath 2017; DBE 2011; DoE 2008). Learners should be acquainted with these unique terms and concepts to communicate and solve problems within the discipline (Ngwenya 2012; Stephenson 2017). The textbooks should therefore provide clear definition of such key terms and concepts, while giving a detailed exposition of core knowledge with clear learning progressions to enhance the development of relevant skills.

Although there is extensive research on textbooks internationally (Bharath 2015; Liang \& Cobern 2013; O'Keeffe 2011; Sunday 2014; Yang \& Sianturi 2017), there is a dearth of textbook research in South Africa (Arek-Bawa \& Dhunpath 2017; Bargate 2012) particularly in high school accounting textbooks. This article thus contributes to knowledge by addressing the gap in the existing literature in accounting, particularly on the quality of high school textbooks. Therefore, the research question for the study is: What is the quality of accounting textbooks in terms of content; structure and organisation; guidance and support; and assessment tasks?

\section{Literature review}

This section reviews relevant literature on the nature of accounting and on the quality of textbooks.

\section{Accounting as a subject}

Over time, the definition of accounting has evolved as changes emerge in the economic environment and society at large (Ngwenya 2012). The focus of accounting is on measuring the performance of entities in addition to the processing and communication of financial events to interested users for decision-making (DBE 2011). The South African secondary school curriculum draws from three fields of accounting, namely 'Financial Accounting, Managerial Accounting and Auditing' (DBE 2011:8). It is envisaged that the knowledge, skills and values acquired from these field will go a long way in preparing learners for the life of work. Topics covered in the Grade 12 accounting curriculum encompass accounting for company transactions, company financial statements and analysis of company accounts in term 1 . The focus for term 2 is on ethics, internal controls, accounting for fixed assets, close corporation, inventory systems and reconciliations. Term 3 dwells on cost accounting and budgeting (DBE 2011:29). While the CAPS for accounting makes provision for ethics and internal controls to be taught on their own, it recommends that the two topics be integrated when teaching other areas.

Like any other subject in the South African secondary school curriculum, assessments for the average Grade 12 learner are both informal (daily) and formal (DBE 2011). The former that can be performed via observation, informal classroom interaction, class activity or homework can be marked by the teacher or learner or both with the aim of providing feedback to enhance learning. The latter include written reports, tests, projects and case study. In terms of examination, students are required to write the mid-year paper, trial paper and end of year examination which accounts for $75 \%$ of total marks (DBE 2011). The CAPS also stipulates that the formal assessments should cater for a wide range of cognitive levels with reference to Bloom's revised taxonomy (DBE 2011). Basic thinking skills synonymous with levels 1 (Remember) and 2 (Understand) account for 30\%; moderate thinking skills, that is, 3 (Apply) and 4 (Analyse) should be 40\%; and high-order thinking skills, that is, 5 (Evaluate) and 6 (Create) are expected to account for $30 \%$ of total cognitive distribution of tasks. Furthermore, it is expected that the examination paper should include questions that elicit problem-solving skills.

As a vital educational resource, textbooks are regarded as the core definition of the curriculum in any discipline including accounting (Bharath 2015; Yang \& Sianturi 2017; Yang, Wang $\& \mathrm{Xu}$ 2015). As such most accounting textbooks align with the curriculum and contain many practice materials that can be used for both classwork and homework while preparing students for exams. However, the extent to which the quality of these textbooks contributes in aiding the attainment of desired educational objective in accounting education remains largely under researched. This article aims to contribute knowledge in this regard.

\section{Good-quality textbooks}

Extant literature has shown that textbooks are regarded as effective tools to ensure better quality in terms of instruction and content (Chirwa \& Naidoo 2016; DoE 2009; Freahat \& Smadi 2014; Gök 2012; Nasser \& Oqlah 2014; Swanepoel 2010; Tarman \& Kuran 2015). However, high-quality teaching is dependent on the availability of quality and appropriate resources. This repositioning of the textbook as a crucial resource in the enhancement of teaching and learning places 
more attention on the quality of textbooks. This means that the availability of high-quality textbooks is one of the critical factors in the successful implementation of the curriculum (Chirwa \& Naidoo 2016; Freahat \& Smadi 2014; Swanepoel 2010). What makes a high-quality textbook depends on the presence of characteristics for specific subject area and curriculum requirements.

A good textbook is therefore one that has the features and characteristics that enable it to support the learners and teachers during the process of learning and teaching (Chirwa \& Naidoo 2016; Gupta \& Marshall 2010; Mahmood 2011). In addition, a textbook is of good quality if the learners who use the textbook achieve the learning outcomes they are supposed to reach (Jones \& Wright 2012; Swanepoel 2010). This implies that the quality of a textbook can therefore be notable in the skills, understanding and application of knowledge attained by the learners who used the textbook. In addition, the extent to which the book guides learners in acquiring these skills and understanding determines the quality of a textbook (Jones \& Wright 2012). Such textbooks also guide the learners in practising the application of knowledge and skill acquired. Consequently, the presence of the characteristics acts as an indicator of the textbooks' effectiveness and quality.

According to the literature, visual presentation, layout or structure, learning activities, content and the language of textbooks are important considerations in the analysis of quality of textbook studies (Bharath 2015; Gök 2012; Liang \& Cobern 2013; Mahmood 2011; Nasser \& Oqlah 2014; O'Keeffe 2011; Sağlam 2012; Sunday 2014; Swanepoel 2010). These characteristics align with some of the attributes prescribed by United Nations Educational, Scientific and Cultural Organisation (UNESCO 2014) to be considered in the production and selection of textbooks. Literature shows that there is a paucity of studies on the quality of high school textbooks in South Africa particularly in accounting and this article aims to fill this gap.

\section{Conceptual framework}

The conceptual framework for the study was developed by combining and adapting Aggarwal's framework (2001) and that of the 2013 South African DBE for analysing textbooks (DBE 2013).

Aggarwal (2001) suggested guidelines upon which the quality of textbooks could be evaluated. These are selection of content, organisation of content, presentation of content, verbal communication and visual communication (illustration). According to the instrument developed by the DBE in 2013, textbooks should be analysed in terms of compliance with the curriculum, content, learning activities and assessment, layout, design and overall quality and teacher guidance. In selecting the criteria for quality investigated in the selected textbooks, we considered the above guidelines provided by the DBE and Aggarwal. We have drawn our quality criteria from key variables of their guidelines. The focus on these key parameters will enable us to overcome time constraints while providing the platform for a rich description of our findings in line with our interpretive paradigm. For the purposes of this article, the focus was on the content, structure and organisation, guidance and support and instructional assessment tasks.

Analysis and comparison of the contents of the two Grade 12 textbooks were carried out by considering how they reflect the requirements of the CAPS curriculum in terms of content coverage, topics structure, language or terminology, accuracy and currentness of content and expertise for content development. In terms of structure and organisation, textbooks analysis was carried out according to the visible structure and format (layout) and logical organisation of topics. Guidance and support provided by the books were analysed according to explicit instructions and illustrations and motivational strategies including visuals used to enhance teaching and learning. Analysis and comparison of the assessment tasks were carried out to determine assessment techniques, question types and to evaluate the cognitive level entrenched in the learning activities in accounting textbooks, and whether the depth of the learning activities is aligned with the CAPS for accounting.

\section{Research methodology and design}

The study adopted the interpretive paradigm as we sought to find meaning and gain understanding of the quality of the selected Grade 12 accounting textbooks. The qualitative content analysis (QCA) was adopted to explore the quality of two Grade 12 accounting textbooks in terms of content, guidance and support, structure and organisation and targeted instructional and assessment strategies. Qualitative content analysis is a flexible technique commonly used in analysing text data (Elo et al. 2014; Hsieh \& Shannon 2005). Drawing from work performed by other scholars, Vaismoradi et al. (2016) describe QCA as a technique used in textual analysis via a 'systematic process of coding, examining of meaning and provision of a description of the social reality through the creation of theme' (p. 100). Even though QCA is widely used in textual analysis because it provides meaningful insight on the content, it is considered inappropriate in a study with open-ended research questions, or those which are exploratory in nature (Kohlbacher 2006; Mayring 2000). However, this limitation does not hold true in this article because the research question is rather specific and direct. To analyse the quality of accounting textbooks, two Grade 12 accounting textbooks were purposively sampled because of their popularity and accessibility. Because the chosen textbooks were CAPS prescribed, they were used by the majority of schools. In addition, as a teacher educator, my experience and observation during teaching practice showed that the two accounting textbooks were the most commonly used in schools. To confirm my observation, we conducted a small-scale informal survey with accounting education students to determine the accounting textbooks that they found to be mostly in use in schools during teaching practice in KwaZulu-Natal. The topic of companies across two 
textbooks was analysed and compared with an attempt to gain a broad perspective on content, structure and organisation, support and guidance and the assessment activities.

The selection of topic - companies - was based on the fact that the topic is regarded as a major and essential topic in the Grade 12 accounting curriculum. Unlike other topics that are introduced in the previous grades, companies are first introduced in Grade 12; as such they are regarded as an example of complex knowledge in the grade. Table 1 provides some key features of each text.

Qualitative content analysis makes room for researchers to use or develop any coding scheme drawing from theory, the data or previous research that can be applied to answer the research question (Krippendorff 2004). Concepts from the conceptual framework developed were used to code the data. Each parameter was rated using the 'low to high' rating scale. A low rating was given if the parameter was not presented or expressed, a moderate rating was given if the parameter was presented but not explicit and a high rating was given for explicit presentation of the parameter in the books.

Trustworthiness was mainly ensued via repeated reading and interaction with the textbooks. Moreover, in line with the requirements of our QCA methodology (Elo et al. 2014), we endeavoured to include relevant examples from the textbooks in support of our interpretations and conclusions.

\section{Ethical consideration}

The ethical code of conduct and requirements set for empirical research by the tertiary institution's ethics committee were adhered to in conducting this study. Issues pertaining to gatekeeper's permission and ethical clearance were given less consideration because of the object of the research, that is, textbooks are openly available in the public domain. Nonetheless, we have adopted pseudonyms (text A and B) in place of the exact names of each textbook to protect the identity of the text producers. Ethical clearance for the study was also obtained from the University of KwaZulu-Natal.

\section{Findings}

The aim of this study was to examine the quality of the two Grade 12 accounting contemporary textbooks in terms of the four parameters: content, structure and organisation, guidance and support and assessment tasks. The findings are presented according to these parameters that compare the content analysis results of each text.

TABLE 1: Sampled textbooks.

\begin{tabular}{lcccc}
\hline Textbooks & $\begin{array}{c}\text { Publication } \\
\text { year }\end{array}$ & $\begin{array}{c}\text { Total number } \\
\text { of pages }\end{array}$ & $\begin{array}{c}\text { Number of } \\
\text { pages analysed }\end{array}$ & $\begin{array}{c}\text { \% number of } \\
\text { pages analysed }\end{array}$ \\
\hline Book A & 2013 & 672 & 292 & 43 \\
Book B & 2013 & 574 & 244 & 46 \\
\hline
\end{tabular}

\section{Content (alignment with the curriculum requirements)}

Analysis and comparison of the contents of the two Grade 12 textbooks were carried out by considering how they present content according to the criteria and reflect the requirements of the CAPS curriculum in terms of content coverage, topics structure and language or terminology.

Findings revealed that both textbooks cover all topics as specified in the CAPS curriculum. This is also evident in both textbooks which are 'topic-structured'. The subject content of accounting is based on the organisation of sub-topics in the curriculum under the three main fields on the disciplines of financial accounting, managerial accounting and managing resources (which incorporates certain aspects of Auditing [DBE 2011]). The CAPS specifically required topics such as 'ethics' and 'internal control' be integrated in the teaching of other topics (DBE 2011). This is stated in Book A, while in Book B, it is implied. Although the content of the two textbooks is aligned with the curriculum requirements, Book $B$ reflects a structure that is more similar to the CAPS, as shown in Table 2.

Book B, like CAPS, uses words and phrases to describe the topic, such as 'analysis' and 'interpretation', which obviously imply the skills involved. In contrast, in Book A, topics are listed and do not give clear indications of the skills expected of learners. Two examples are shown in Table 2.

In most cases, the language or terminology used in Book A is different from Book B, as indicated in Table 3. Book A contains more real-life connections and a larger number of technical terms that are used in the accounting discipline because of the nature of the subject.

Although the textbooks use different terminology, Book B is compatible with the CAPS. Book A provides terminology

TABLE 2: Comparison of naming of topics.

\begin{tabular}{lll}
\hline CAPS - accounting & Book A & Book B \\
\hline $\begin{array}{l}\text { Definition and explanation of } \\
\text { accounting concepts unique } \\
\text { to companies }\end{array}$ & $\begin{array}{l}\text { Basic concepts and } \\
\text { unique transactions }\end{array}$ & $\begin{array}{l}\text { Definition and explanation of } \\
\text { accounting concepts unique } \\
\text { to companies }\end{array}$ \\
$\begin{array}{l}\text { Preparation of final accounts } \\
\begin{array}{l}\text { and detailed financial } \\
\text { statements of a company }\end{array}\end{array}$ & Financial reporting & $\begin{array}{l}\text { Preparation of final accounts } \\
\text { and detailed financial } \\
\text { statements of a company }\end{array}$
\end{tabular}

statements of a company statements of a company

Source: Please see the full reference list of the article, Ngwenya, J. \& Arek-Bawa, O.A., 2019, 'Exploring the quality of Grade 12 accounting education textbooks', The Journal for Transdisciplinary Research in Southern Africa 15(1), a662. https://doi.org/10.4102/td. v15i1.662, for more information

CAPS, Curriculum and Assessment Policy Statement.

TABLE 3: Comparison of terminology used in textbooks.

\begin{tabular}{lll}
\hline CAPS - accounting & Book A & Book B \\
\hline $\begin{array}{l}\text { Financial accounting of } \\
\text { companies }\end{array}$ & Companies & $\begin{array}{l}\text { Financial accounting of } \\
\text { companies }\end{array}$ \\
$\begin{array}{l}\text { Preparation of financial } \\
\text { statements Financial }\end{array}$ & Financial reporting & $\begin{array}{l}\text { Preparation of financial } \\
\text { statements }\end{array}$ \\
Year-end adjustments & Year-end procedures & $\begin{array}{l}\text { Year-end adjustments } \\
\text { Ratios }\end{array}$ \\
\hline
\end{tabular}

Source: Please see the full reference list of the article, Ngwenya, J. \& Arek-Bawa, O.A., 2019, 'Exploring the quality of Grade 12 accounting education textbooks', The Journal for Transdisciplinary Research in Southern Africa 15(1), a662. https://doi.org/10.4102/td. v15i1.662, for more information

CAPS, Curriculum and Assessment Policy Statement. 
BOX 1: New terminology.

\section{New terminology}

The Income Statement is also referred to as a statement of comprehensive income.

Source: Hall, T., Woodroffe, D., Singh, P. \& Aboobaker, H., 2013, New era. Accounting learner's book. Grade 12, p. 36, New Generations Publishers, Pietermaritzburg

changes to update the teacher and the learners about the changes in practice. What is evident in Book A is that new terminology is provided in brackets, for example balance sheet is now called statement of financial position (see Box 1).

Both textbooks are designed along the lines of progression within the grade from one topic to another. They both reflect increasing levels of complexity in terms of content, concept or skill as the chapter progresses. Topics generally commence from understanding of basic concepts and progress through application, and ultimately analysis, interpretation, evaluation and creative problem-solving. Both books are consistent with the CAPS in this regard.

Both textbooks reflect specific weeks for topics such as problem solving, reporting and control of fixed assets, ethical considerations, internal audit and control processes. Furthermore, in both textbooks, Business Ethics and Internal Control related to companies are integrated under financial reporting tasks, for instance Book $A$, page 103 and 141 and Book $B$, section 4.3, page 14 . However, Book A reminds the teachers to reinforce these topics by integrating them in other topics as seen on page 12 .

Book A contains information about names of authors and their qualifications. Similarly, the names of editor, expert consultants, cover and layout designer and their qualifications are given. On the contrary, Book B provides the names of authors without their credentials.

\section{Structure and organisation of the textbooks}

Analysis and comparison of the structure and organisation of the two textbooks was carried out according to the visible structure and format, and logical organisation of topics. Considerable difference between the books in terms of structure was noted.

Both books provide a table of contents which shows all of the sub-topics in great detail with their page numbers. Although topics and sub-topics are very clear, Book A's table of contents uses different fonts in different colours for attractiveness. Furthermore, Book A is divided into modules. On the other hand, Book B is divided into four terms that are divided into units. Each unit is divided into sections. This division is compatible with CAPS.

In Book B, the topic 'Financial Accounting of Companies' is covered in the first term and divided into four units, while in Book $\mathrm{A}$, the topic is divided into five modules. The difference is because of the fact that in Book A 'GAAP, Year-end Procedures and final accounts' are covered separately in module 2, while company financial statements are covered in module 3. In Book B, these two sub-topics are covered in one unit.

Book A starts by introducing the book to the learner and the teacher. The introduction reminds the teacher about the changes to the content in the curriculum because of the new Companies Act and the latest developments in the subject, for example International Financial Reporting Standards and King Codes. The introduction also gives information about the general structure of the textbook and instructions about how to use the book regarding the choice and variation of tasks and the depth and breadth of content. The book also provides a brief discussion on the nature and the scope of the subject of accounting. In contrast, the authors of Book B do not provide a brief overview about the book to introduce the book to the teacher and the learners.

In Book A, each module provides a detailed introduction that gives an outline of what is covered in that particular module. The textbook also provides in-depth background information about the sub-topic. On the other hand, Book B mainly provides a very brief introduction of each unit or topic. However, in some instances, there was no introduction, for instance, unit 1- Financial Accounting of Companies, page 1.

Furthermore, in Book A, at the beginning of each module, the teacher is reminded of the prior knowledge that a learner is expected to have before attempting the new topic. This is emphasised with bold, colour treatment of font style. Book A also provides detailed module outcomes and clearly stated objectives at the beginning of all sub-topics for companies. This helps students to follow the topics step by step. In contrast, Book B is silent.

\section{Guidance and support}

Guidance and support provided by the books were analysed according to explicit instructions and illustrations and motivational strategies used to enhance teaching and learning. In both books every activity provides the learners with the information needed to complete the tasks and what is required as shown in Box 2.

In Book A, there are graphics and photographs that help to draw the learner's visual interest and attention. This helps the learner to relate and engage more with the text and to connect new knowledge to real or daily life (Sunday 2014). In addition, Book A provides 'sweat drop' icons to assist teachers in selecting appropriate tasks according to the degrees of challenge and importance. The book also uses graphic texts in different colours and fonts to emphasise the new knowledge. It further provides a checklist at the end of each sub-topic to assist the learners to determine if they have covered all the content and skills under the sub-topic. Book A provides information boxes about reflection time and the use of rubrics. In these boxes, important information about the topic is emphasised. Book B presents a type of text box called note pads that were not introduced at the beginning of Book B to inform the teacher about their use. 
BOX 2: Example of instructions to learners.

\section{The information that follows was taken from the accounting records of ...}

Required:

(1) Record the transactions in the relevant journal.

(2) Post to the following accounts in the General Ledger

Information:

The following balance appeared in the General Ledger of ...

Source: Hall, T., Woodroffe, D., Singh, P. \& Aboobaker, H., 2013, New era. Accounting learner's book. Grade 12, p. 27 (activity 1.10), New Generations Publishers, Pietermaritzburg

Book B provides formal assessment at the end of the term which helps teachers with the examples of assessment tasks that should be given to the learners at the end of each term. Both books contain a glossary of technical terms used in the books. Both also provide resources that include a workbook for learners, teacher guide and solutions book.

\section{Assessment tasks}

The number and the type of assessment tasks relating to companies were analysed. Furthermore, the extent to which the assessment activities cover a sufficiently wide range of intellectual and cognitive skills was also determined.

In both textbooks, the assessment activities incorporate different styles of assessment such as group, peer and selfassessment. Textbooks present different kinds of activities such as experiments, group studies, research, writing reports and making presentations. In each sub-topic in both textbooks, examples are followed by tasks which cover essential prior knowledge and the basics of the topic. These tasks are then followed by practice activities. However, a noticeable difference between the books is the number of assessment tasks, as depicted in Table 4. Although Book A provides more in-text practice activities than Book $\mathrm{B}$, the book does not provide revision exercises at the end of the unit, while Book $B$ reflects eight revision exercises at the end of the topic term or unit. In addition, in Book B, there is one formal assessment at the end of the unit which is divided into eight sections that cover all the sub-topics, while Book A is silent on this point.

All assessment tasks on companies were analysed to examine the extent to which the activities cover a sufficiently wide range of intellectual and cognitive skills. Bloom's revised taxonomy (Anderson \& Krathwohl 2001) was used as an effective criterion to assess learning activities. The taxonomy was adapted to eight cognitive learning domains. Application was divided into basic and advanced application, while analysis was divided into low-level and advanced-level analytical skills. In the low-level application questions, learners are required to perform or apply a standard procedure or calculation, while in advanced application questions, such as in Box 3, learners are required to perform more complex accounting procedures which involve more in-depth processes.

In terms of low-level analysis, learners are needed to understand the concepts, interpret and analyse the information provided to determine the appropriate calculation. In advanced-level analysis, learners are required to make use of more advanced analytical skills in interpreting
TABLE 4: Type and the number of assessment tasks.

\begin{tabular}{lcc}
\hline Assessment tasks & $\begin{array}{c}\text { Book A: Number of } \\
\text { assessment tasks }\end{array}$ & $\begin{array}{c}\text { Book B: Number of } \\
\text { assessment tasks }\end{array}$ \\
\hline Practice activities (in-text activities) & 107 & 81 \\
Revision exercises - end of unit & - & 8 \\
Revision exercises - end of book & 10 & 11 \\
Formal assessment - end of unit & - & $\begin{array}{c}1 \text { divided into } \\
8 \text { activities }\end{array}$ \\
Exam papers - exemplar & 2 & 2 \\
\hline Total number of assessment tasks & 119 & 103 \\
\hline
\end{tabular}

BOX 3: Example of more advanced application question.

\section{More advanced application question}

The following information was taken from the accounting records of JS Limited for the year ended 28 February 2013 and February 2014. JS Limited has a registered authorised share capital of 5200000 ordinary shares. Information provided includes extract from the Income Statements for 2013 and 2014, extract from the includes extract from the Income Statements for 2013 and 2014, extract fror (adjustments).

Required:

Complete the note in respect of the reconciliation of Net profit before tax with Cash Generated from operations.

Source: Seevnarain, J., Seevnarain, M. \& Thaver, V., 2013, Top class. Accounting Grade 12. Learner's book, p. 146 (activity 1.61), Shuter \& Shooter, Pietermaritzburg

TABLE 5: Cognitive level and the percentage of assessment tasks per textbook.

\begin{tabular}{lcc}
\hline Cognitive levels & Book A & Book B \\
\hline Recall (\%) & 5 & 4 \\
Comprehension (\%) & 12 & 8 \\
Low-level application (\%) & 12 & 8 \\
Advanced-level application (\%) & 12 & 8 \\
Interpretation \& low-level analysis (\%) & 5 & 4 \\
Advanced analysis skills (\%) & 6 & 5 \\
Evaluative skills (\%) & 4 & 3 \\
Creative and problem-solving skills (\%) & 3 & 5 \\
\hline
\end{tabular}

BOX 4: Example of evaluation question.

\section{Information includes:}

The extract from the income statement, balance sheet and notes to the balance sheet and financial indicators for the previous year:

(1) Should the directors of this company be satisfied with the net profit and control over expenses? Explain.

(2) Comment on the financial leverage of the company.

Source: Hall, T., Woodroffe, D., Singh, P. \& Aboobaker, H., 2013, New era. Accounting learner's book. Grade 12, p. 249 (activity 12.6), New Generations Publishers, Pietermaritzburg

the data given in calculation of financial indicators in an unfamiliar context (i.e. companies). All assessment tasks or activities in both textbooks were classified, analysed and codified according to remembering, understanding, basic application, advanced application, basic analysis, advanced analysis, evaluating and creating to examine the extent of intellectual activity required to perform a task.

The process required to perform the task and the level of cognitive demand required by the task were analysed using the framework. Also, operations required by the task were analysed to determine the processes required in doing the task (see Table 5).

Book A provides more in-text practice activities than Book B. This is also evident in Table 5 which reflects more percentage of activities in each cognitive level. Evaluation questions require learners to assess financial information and draw conclusions to make judgements and then back their conclusions with evidence, as seen in Box 4. 
The evident difference is that Book B has more creative and problem-solving activities where learners are required to make evaluative judgements using the financial information provided to expand on their evaluative judgements by formulating and providing opinion and explanation for decisions made. However, both books do not have creative problem-solving questions that require learners to identify real-life problems from a range of financial information, quote the relevant information to support their opinions on the problems and provide valid and appropriate solutions.

\section{Discussion}

The findings of the study are presented by considering how the textbooks present content, structure, support and guidance and assessment tasks according to the conceptual framework and how the textbooks reflect the requirements of the curriculum.

Findings revealed that both textbooks cover all topics adequately as stipulated in the curriculum. In other words, by working through the chapters relating to companies from each textbook, the learner would be exposed to the knowledge, skills and intent of the curriculum. In accounting, although the emphasis is on the progression of knowledge, there are topics that cannot be taught in isolation as they need to be integrated and taught simultaneously with other topics to strengthen the development of conceptual understanding (Ngwenya 2012; Umalusi 2014). This integration was evident in both books.

From the findings, it was evident that textbooks lack homogeneity in some of the parameters of the quality in terms of content examined in each textbook. Although there is uniformity in terms of content coverage, the depth or extent of coverage differs as indicated under data presentation. In addition, the subject content of accounting is based on the organisation of sub-topics in the curriculum under the three main fields of accounting (i.e. financial accounting, managerial accounting and auditing [DBE 2011]). Irrespective of the fact that the subject consists of these three distinct fields, the curriculum emphasises a holistic approach to teaching, such that these fields are integrated to facilitate a conceptual understanding of accounting (DBE 2011; Ngwenya 2016). Although both textbooks cover all topics as specified in the CAPS curriculum, Book A expressly states the three fields incorporated in the subject domain, while Book B is silent. Such express statements in Book A could be a reminder for teachers to integrate the teaching and learning activities from the three fields thus enabling learners to make connections between the different fields towards the attainment of disciplinary expertise (Ngwenya 2016). Thus, in this regard, Book A provides better support.

To acquaint users with the realities, the nature of the subject of accounting makes it imperative for regular revision of teaching resources and textbooks to incorporate current accounting standards and legislations (Bargate 2012). Book A provides terminology changes to update the teacher and the learners about the changes in practice, but Book $\mathrm{B}$, which is heavily attuned to the CAPS curriculum, makes no mention of these changes.

Expertise for content development depends on the quality of authorship and the sources used in writing the text (Tarman \& Kuran 2015). The inclusion of author credentials in the textbook attests to their calibre as it gives a clear indication of the authors' experience, qualification and level of expertise in the field of accounting and society in general. This increases the credibility of the information provided in the book. In this regard, Book A appears positioned as a more credible resource than Book B.

According to Tarman and Kuran (2015), the structural features of the textbook play an important role in what is taught in class. These features, which can either aid or hinder comprehension, must be designed to assist and facilitate learning the ideas presented in the text (O'Keeffe 2011). They serve as clues to acquaint users with the topics included in the chapter on companies and the order in which they are presented (Sağlam 2012). In both books, the structure of the content is made apparent by means of functional devices, including a detailed table of contents, chapter titles and headings.

In the CAPS curriculum for accounting, emphasis is placed on conceptual coherence, sequence and progression of knowledge which is evident in each section and within the topic. This suggests that learning is developmental and underpinned by the notion of hierarchy of knowledge and skills (Bharath 2015; DBE 2011). In both textbooks, the content is sequenced and paced in such a way as to assist the teacher with planning and teaching. This was also evident in the assessment tasks that were based on the hierarchy of knowledge and skills as they are influenced by the sequence of topics (Arek-Bawa \& Dhunpath 2017). By providing in-text assessments along with the concepts under each sub-topic, both textbooks facilitated ease of comprehension (Sunday 2014; Widodo 2007).

The findings also revealed a lack of consistency in terms of structure and organisation in some of the parameters of the quality examined in each textbook. Background information for each topic assists learners to understand the new concepts (Mahmood 2011). However, Book B provides a very brief introduction and is sometimes silent in this regard, while Book A provides a detailed introduction of the textbook and each module as well as in-depth background information about the sub-topics. In essence, users of Book B may not receive a preview of the content in each unit.

On the other hand, Book B is structured in a way that is consistent with the accounting curriculum in terms of the naming and structure of the topics and terminology. In addition, the fact that the topics are arranged on a termly basis in line with the CAPS curriculum implies that the 
teacher using Book B may not need to refer to the curriculum regularly for guidance. Book B, like CAPS, uses nouns that obviously imply the skills involved to describe the topic. This gives guidance on how deep the teachers are expected to go when teaching the topic. In contrast in Book A, topics are listed and do not give clear indications of the skills expected of learners.

Research shows that better learning occurs when learners build on prior knowledge to strengthen the connections between existing knowledge and the new concepts about to be learnt (Freahat \& Smadi 2014; Ngwenya 2016; Widodo 2007). In this study, textbooks showed significant difference in terms of the prior knowledge that a learner is expected to have before attempting the new topic. Book A provides a detailed discussion of prior knowledge of each module or topic. Furthermore, module outcomes and objectives are viewed to be essential at the beginning of all sub-topics in assisting teachers in knowing what to teach and help learners to understand what to learn, and Book B was found to be silent in this regard. As such, users of Book B may be unaware of the key learning points on each topic.

The clarity of textbook instructions is very crucial because explicit communication of the skills to be learnt helps to improve thinking skills (Sunday 2014). Both books provide explicit instructions which are clear as they provide appropriate instructions on exactly how to perform the task. However, the findings revealed a lack of homogeneity in terms of visuals in both books. Visuals are deemed important in the communication of accounting concepts (Stephenson 2017; Sunday 2014). This could be adduced to the fact that graphics are concise and memorable, and they make relationships within the information readily apparent, thereby helping in elaborating or expanding different concepts (Aggarwal 2001; Widodo 2007). However, Chirwa and Naidoo (2016) also contend that the cluttering of the textbook with irrelevant distracting features may reduce the effectiveness of the text. Nonetheless, in accounting, there is a need for textbooks to contain a reasonable number of features such as balance sheets, income statements and other types of financial figures to aid the instruction and to consolidate learning. In Book A, there are well-designed graphics and helpful features that support learning by presenting examples and revealing underlying knowledge structures that help learners make the required connections to take learning further. This is consistent with Sunday (2014), who argues that graphics should be included in textbooks in a manner that attracts, engages meaningfully and stimulates the imagination to promote learners' understanding. While photographs and illustrations are seen to be presenting sufficient information, Book B provides minimal information. By implication, Book A has a greater propensity to engage and stimulate learning by providing more guidance and support than Book B.

The checklist at the end of each sub-topic is regarded as an effective way of confirming that the learner has understood the section, or she or he needs more clarity on some aspects of the sub-topic (Jones \& Wright 2012). Such a checklist could be likened to sectional summaries which are found to be helpful in emphasising key concepts and learning points (Sağlam 2012). In this regard, Book A can be termed more user-friendly (user-oriented) than Book B, as users do not have to scan through detailed topic explanations to extract vital points (Sağlam 2012). On the other hand, by not providing outright summaries, Book B could inadvertently be facilitating the development of higher level learning skills as students learn to discriminate and sift out relevant vital points.

Assessment activities must cover the content of the subject as well as the range of skills and the cognitive levels to cater for different abilities of learners (Freahat \& Smadi 2014). Although there is no balanced coverage of cognitive skills of all levels, a range of varied activities is provided. In both books, there are activities that are appropriate for the skills and knowledge described in the curriculum or learning expectations. These activities provide opportunities for students to engage in higher order thinking and problem solving, to apply concepts and procedures and to communicate their understanding. This is contrary to the outcome of O'Keeffe's (2011) and Sağlam's (2012) studies, which concluded that Ireland, Turkey and Singapore textbooks mainly emphasised routine procedures of low to moderate complexity with little consideration for conceptual understanding. While in both books, creative thinking skills are encouraged, learners are only involved in less structured problems: there are no unstructured open-ended questions where learners are required to use deep processing critical thinking skills.

\section{Conclusion and recommendations}

Stemming from the importance of textbooks in the South African schooling system, this article sought to examine the quality of two Grade 12 CAPS-approved accounting textbooks in terms of content; structure and organisation; guidance and support; and assessment tasks. Even though an in-depth analysis of the topic related to companies revealed some similarities in relation to the parameters investigated, some differences were also identified.

The publishers of the textbooks have performed well in aligning with the curriculum requirement in terms of content coverage. In both books, connections between related topics or concepts were highlighted and practice questions with real-life situations were provided to make them more understandable. Both books used functional devices including a detailed table of contents, chapter titles and headings to structure the content covered. In terms of assessments, both textbooks provided a wide range of activities albeit an imbalanced load across the cognitive levels.

However, Book A appears more supportive as it acquainted users with the three fields of accounting incorporated in the 
curriculum, and consistently provided a detailed introduction to each topic with clearly stated learning outcomes. Appropriate consideration was given to the learners' prior knowledge and learning experience. Book $\mathrm{A}$ also did well in providing suitable graphics and other features such as sweat icons to attract learners' attention, motivate learning and stimulate thinking while guiding the teacher. By implication, Book A had a greater propensity to engage and stimulate learning as it offered better guidance and support to the teachers and learners than Book B.

Although Book B was found wanting in providing the above features, it kept pace with the curriculum in structuring the topics on a termly basis such that the teacher could have limited recourse to the CAPS curriculum. While Book B is consistent with the CAPS for accounting in terms of structure and naming of the topics, the book does not provide detailed introduction and in-depth background information, module outcomes and objectives and prior knowledge. Nonetheless, a synopsis or summary of the key points offered in Book B is known to be one of the key attributes of quality writing (Jones \& Wright 2012).

Furthermore, teachers who are using Book B only will not be able to provide learners with more knowledge other than what is in CAPS which is too prescriptive in nature (Ozturk 2011; Umalusi 2014). The teachers will be teaching learners to pass Grade 12, in other words, teaching to the examination. This could account for the concerns by higher education institutions that learners are being coached at school to pass Grade 12 examinations, instead of being taught to think critically and logically about concepts (Ramatlapana \& Makonye 2012; Stephenson 2017). The book limits the teacher's ability to focus on a holistic understanding of the subject matter as she or he is expected to adhere strictly to the curriculum, rather than use professional judgement to think and act more spontaneously in the best interests of the learners (Ozturk 2011). These shortfalls suggest that the teachers who are using the book will have to consult other books as the book is lacking in fully supporting teachers. It is recommended that at least two textbooks should be prescribed, especially in Grade 12, to supplement each other.

It is indeed remarkable that there were questions in every cognitive level although the percentages differed. However, it is suggested that more unstructured open-ended questions aimed at developing the student's inquiry and creative instincts should be included in the textbooks to prepare them for subsequent tertiary learning and future work demands. This is consistent with research that some of the problems experienced by first year accounting students emanate from inadequate preparation of learners at secondary level for a tertiary education (Ngwenya 2016; Stephenson 2017).

Furthermore, accounting teachers, especially teachers who are known to depend heavily on the textbook, and subject specialists are advised to carefully consider the quality of accounting textbooks in terms of guidance and support provided to enhance learning and teaching, even though they are all CAPS-approved. Producers of textbooks can also benefit by considering and utilising the outcome of this research to improve the quality of future accounting textbooks.

As textbooks are an important controlling tool used to ensure compliance and coverage of the curriculum (Ozturk 2011), teachers tend to stick rigidly to the prescribed textbooks. However, the prescribed textbooks do not adequately support teaching and learning. As such, it is suggested that teachers must be circumspect in their use of textbooks. The shortcomings in both textbooks such as the lack of creative problem-solving assessment tasks should be ameliorated by teacher interventions to attain the desired educational objectives. In addition to the use of past Grade 12 matric papers, experienced educators can develop their own resources (assessments activities) or turn to other sources such as the Internet.

This article is not without its limitations. Our analysis was based on one chapter (companies) in two Grade 12 accounting textbooks as we sought insight through an in-depth review. It is possible that a wider range could yield different results. Although we acknowledge the fact that there are other parameters of quality, we assessed the quality of the textbooks based on four characteristics, namely content; structure and organisation; guidance and support; and targeted instructional and assessment tasks. It is likely that the inclusion or use of other characteristics could lead to different conclusions. Consequently, there is room for further research on the quality of the accounting textbooks used in South Africa.

Subsequent research on quality could involve more textbooks and chapters. Other scholars could focus on accounting textbooks used across the three grades in the Further Education and Training Phase. Yet, others could increase the criteria assessing criteria in their review of accounting textbooks. A review of the quality of Grade 12 textbooks with commerce disciplines will also be worthwhile.

\section{Acknowledgements Competing interests}

The authors declare that they have no financial or personal relationships that may have inappropriately influenced them in writing this article.

\section{Author's contributions}

J.N. conceptualised the study. J.N. and O.A-B. analysed data. J.N. wrote the first draft and O.A-B. conducted the literature review. All authors read and approved the final version of the manuscript.

\section{Funding}

This research received no specific grant from any funding agency in the public, commercial or not-for-profit sectors. 


\section{Data availability statement}

Data sharing is not applicable to this article as no new data were created or analysed in this study.

\section{Disclaimer}

The views and opinions expressed in this article are those of the authors and do not necessarily reflect the official policy or position of any affiliated agency of the authors.

\section{References}

Abbott, J.I. \& Palatnik, B.R., 2018, 'Students' perceptions of their accounting class: Implications for instructors', Accounting Education 27(1), 72-93, viewed n.d., from https://www.tandfonline.com/doi/pdf/10.1080/09639284.2017.1381032.

Adeoye, B.F. \& Olabiyi, O.S., 2011, 'Basic technology textbooks in Nigerian secondary schools', A Quality and Content Analysis 14(2), 153-168, viewed n.d., from Home. hiroshima-u.ac.jp/cice/wp-content/uploads/2014/03/14-2-10.

Aggarwal, J.C., 2001, Principles, methods and techniques of teaching, 2nd edn., VIKAS publishing, New Delhi.

Anderson, L.D. \& Krathwohl, D. (eds.), 2001, A taxonomy for learning, teaching and assessing: A revision of Bloom's taxonomy of educational objectives, Addison Wesley Longman, Inc, New York.

Arek-Bawa, O., 2018, 'Cognitive demand of assessment activities in level-one financial accounting textbooks in selected African countries', PhD thesis, University of KwaZulu-Natal, Durban.

Arek-Bawa, O. \& Dhunpath, R., 2017, 'Assessment and cognitive demand in higher education accounting textbooks', Alternations 24(2), 140-166. https://doi. org/10.29086/2519-5476/2017/v24n2a8

Barac, K. \& Du Plessis, L., 2014, 'Teaching pervasive skills to South African accounting students', Southern African Business Review 18(1), 53-79, viewed n.d., from https://www.unisa.ac.za/static/corporate_web/Content/Colleges/CEMS.

Bargate, K., 2012, 'Criteria considered by accounting faculty when selecting and prescribing textbooks: A South African Study', International Journal of Humanities and Social Science 2(7), 114-122.

Bharath, P., 2015, 'An investigation of progression in historical thinking in South African History textbooks', PhD thesis, University of KwaZulu-Natal, Pietermaritzburg.

Chirwa, G.W. \& Naidoo, D., 2016, 'Teachers' perceptions of the quality of the new expressive arts textbooks for Malawi primary schools', South African Journal of Childhood Education 6(1), 1-10. https://doi.org/10.4102/sajce.v6i1.411

Davidson, R.A. \& Baldwin, B.A., 2005, 'Cognitive skills objectives in intermediate accounting textbooks: Evidence from end-of-chapter material', Journal of Accounting Education 23(2), 79-95. https://doi.org/10.1016/j.jaccedu.2005. 05.001

Department of Education (DOE), 2008, Learning programme guidelines, accounting grade $10-12$, Government Printers, Pretoria.

Department of Education (DOE), 2009, Curriculum news. Improving the quality of learning and teaching. Planning for 2010 and beyond, Government Printers, Pretoria.

Department of Basic Education (DBE), 2011, Curriculum and assessment policy statement: Accounting, Government Printers, Pretoria.

Department of Basic Education (DBE), 2013, Guiding criteria for selecting textbooks, Government Printers, Pretoria. Unpublished.

Elo, S., Kääriäinen, M., Kanste, O., Pölkki, T., Utriainen, K. \& Kyngäs, H., 2014 'Qualitative content analysis', Sage Open 4(1), 2158244014522633. https://doi. org/10.1177/2158244014522633

Eskola, A., 2011, 'Good learning in accounting phenomenographic study on experiences of Finnish higher education student', PhD thesis, University of Jyvaskyla, Finland.

Freahat, N.M. \& Smadi, O.M., 2014, 'Lower-order and higher-order reading questions in secondary and university level EFL textbooks in Jordan', Theory and Practice in Language Studies 4(9), 1804-1813. https://doi.org/10.4304/tpls.4.9.1804-1813

Gök, T.I., 2012, 'Comparative analysis of biology textbooks with regard to cellular respiration and photosynthesis', Master's thesis, Bilkent University, Ankara.

Gupta, S. \& Marshall, L.L., 2010, 'Congruence between entry-level accountants' required competencies and accounting textbooks', Academy of Educational Leadership Journal 14(1), 1-12.

Hall, T., Woodroffe, D., Singh, P. \& Aboobaker, H., 2013, New era. Accounting learner's book. Grade 12, New Generations Publishers, Pietermaritzburg.
Hsieh, H.F. \& Shannon, S.E., 2005, 'Three approaches to qualitative content analysis', Qualitative Health Research 15(9), 1277-1288. https://doi. org/10.1177/1049732305276687

Jones, S.H. \& Wright, M., 2012, 'Does cognitive style affect performance on accounting examination questions?', Global Perspectives on Accounting Education 9, 31-52.

Kohlbacher, F., 2006, 'The use of qualitative content analysis in case study research', Forum: Qualitative Social Research 7(1), 1-30.

Krippendorff, K., 2004, 'Reliability in content analysis', Human Communication Research 30(3), 411-433. https://doi.org/10.1093/hcr/30.3.411

Liang, L. \& Cobern, W.W., 2013, 'Analysis of a typical Chinese high school biology textbook using the AAAS textbook standards', Eurasia Journal of Mathematics, Science \& Technology Education 9(4), 329-336

Mahmood, K., 2011, 'Conformity to quality characteristics of textbooks: The illusion of textbook evaluation in Pakistan', Journal of Research and Reflections in Education 5(2), 170190. https://doi.org/10.20533/licej.2040.2589.2011.0069

Mayring, P., 2000, 'Qualitative content analysis', Forum: Qualitative Social Research $1(2), 1-10$.

Ngwenya, J.C., 2016, 'Rural as potential, not pathology: A case of rural accounting teachers' practices in South Africa', Journal of Human Ecology 53(1), 39-48. teachers practices in South Africa, Journal of

Ngwenya, J.C., 2012, 'Formative assessment in accounting: Exploring teachers' understanding and practices', PhD thesis, University of KwaZulu-Natal, Durban.

O'Keeffe, L., 2011, 'An investigation into the nature of mathematics textbooks at junior cycle and their role in mathematics education', PhD thesis, University of Limerick, Limerick.

Ozturk, I.H., 2011, 'Curriculum reform and teacher autonomy in Turkey: The case of the history teaching', International Journal of Instruction 4(2), 113-128, viewed n.d., from https://files.eric.ed.gov/fulltext/ED522675.pdf.

Nasser, M.F. \& Oqlah, M.S., 2014, 'Lower-order and higher-order reading questions in secondary and university level EFL textbooks in Jordan', Theory and Practice in Language Studies 4(9), 1804-1813. http://doi.org/10.4304/tpls.4.9.1804-1813

Ramatlapana, K. \& Makonye, J.P., 2012, 'From too much freedom to too much restriction: The case of teacher autonomy from national curriculum statement (NCS) to curriculum and assessment statement (CAPS)', Africa Education Review 9(1), S7-S25. https://doi.org/10.1080/18146627.2012.753185

Sağlam, R., 2012, 'A comparative analysis of quadratics in mathematics textbooks from Turkey, Singapore, and the International Baccalaureate Diploma Programme', Master's thesis, Bilkent University, Ankara, Turkey.

Seevnarain, J., Seevnarain, M. \& Thaver, V., 2013, Top class. Accounting Grade 12. Learner's book, Shuter \& Shooter, Pietermaritzburg.

Stephenson, S.S., 2017, 'Accounting community of practice pedagogy: A course management invention for developing personal competencies in accounting education', Accounting Education 26(1), 3-27, viewed n.d., from https://www. education', Accounting Education 26(1), 3-27, viewed
tandfonline.com/eprint/aSFBuRss8xGu6YNM9Jq4/full.

Sunday, A.S., 2014, 'Mathematics textbook analysis: A study on recommended mathematics textbooks in school use in southwestern states of Nigeria', European mathematics textbooks in school use in southwestern states of Nigeria', European Scientific Journal Special Edition 1, 140-151, view/.
org/index.php/esj/article/viewFile/4085/3919.

Swanepoel, S., 2010, 'The assessment of the quality of science education textbooks: Conceptual frameworks and instruments for analysis', PhD thesis, University of South Africa, Pretoria.

Tarmana, B. \& Kuran, B., 2015, 'Examination of the cognitive level of questions in social studies textbooks and the views of teachers based on Bloom taxonomy', Educational Sciences: Theory \& Practice 15(1), 213-222.

Umalusi, 2014, What's in the CAPS package? Business, commerce and management. A comparative study of the national curriculum statement (NCS) and the curriculum and assessment policy statement (CAPS), South Africa, Pretoria.

United Nations Educational, Scientific and Cultural Organization (UNESCO), 2014 Textbooks and learning resources: Guidelines for developers and users, viewed 18 December 2018, from https://unesdoc.unesco.org/ark:/48223/pf0000226135_ eng.

Vaismoradi, M., Jones, J., Turunen, H. \& Snelgrove, S., 2016, 'Theme development in qualitative content analysis and thematic analysis', Journal of Nursing Education and Practice 6(5), 100-110. https://doi.org/10.5430/jnep.v6n5p100

Widodo, H.P., 2007, 'Textbook analysis on college academic writing', TEFLIN Journa 18(2), 109-122. http://doi.org/10.15639/teflinjournal.v18i2/109-122

Yang, D.-C. \& Sianturi, I.A., 2017, 'An analysis of Singaporean versus Indonesian textbooks based on trigonometry content', Eurasia Journal of Mathematics Science and Technology Education 13(7), 3829-3848. https://doi.org/10.12973/ eurasia.2017.00760a

Yang, D., Wang, Z. \& Xu, D., 2015, 'A comparison of questions and tasks in geography textbooks before and after curriculum reform in China', Review of International Geographical Education Online 5(3), 231-248. 